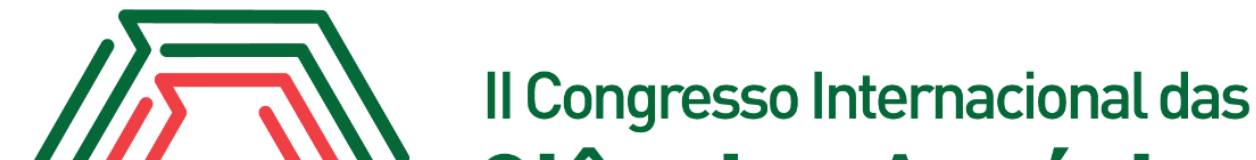 Ciências Agrárias COINTER - PDVAgro 2017
}

\section{AVALIAÇÃo do TEOR DE ALUMÍNIO TROCÁ VEL E SATURAÇÃO POR ALUMÍNIO EM DIFERENTES USOS E COBERTURA DO SOLO}

\author{
Apresentação: Pôster \\ Jôsi Mylena de Brito Santos ${ }^{1}$; Letícia Coelho Vaz Silva ${ }^{2}$; João Carlos dos Santos Duarte ${ }^{3}$; \\ Gabriel Anderson Martins dos Santos ${ }^{4}$; Éder Silva de Oliveira ${ }^{5}$
}

\section{Introdução}

A maior parte da degradação dos sistemas naturais presentes no meio ambiente, se dá pelo manejo inadequado do solo para produção de alimentos e atividade voltadas a fins industriais, onde a retirada da cobertura vegetal e introdução de culturas, junto a pratica de manejo equivocados ocasiona o desequilíbrio entre o solo e o meio, modificando suas propriedades químicas, físicas e biológicas (CENTURION, CARDOSO e NATALE, 2001).

Tal qual Caries et al.;(2004) apresenta em seu estudo, outros autores afirmam a importância da mensuração do teor de alumínio presente no solo, pois sua alta concentração está diretamente ligado a acidez do solo e consequentemente ao mal desenvolvimento de raízes, limitando a produção agrícola em áreas no mundo.

Este estudo visa analisar o teor de alumínio trocável e saturação de alumino presente em um solo com diferentes usos e coberturas, de forma a mostrar sua variação em duas profundidades. $\mathrm{O}$ clima é um dos principais fatores edáfoclimaticos que definem qual o tipo e a forma de manejo é mais adequado em diferentes zonas e culturas (OLIVEIRA; BEZERRA, 2013). A área de estudo apresenta, segundo a classificação de Köppen, tipo Am que corresponde a categoria de local superúmido, com altas temperaturas, baixa amplitude térmica e precipitações ditas ambulantes, além disso, a predominância do solo no nordeste paraense é do tipo Latossolo Amarelo distrófico, com textura média (MEDEIROS, 2012).

\section{Fundamentação Teórica}

Segundo Oliveira e Bezerra (2013), o plantio de cereais e grão leguminosos ocupa grandes

\footnotetext{
${ }^{1}$ Engenharia Ambiental e Energias Renováveis, Universidade Federal Rural da Amazônia, josimbsantos@ gmail.com;

${ }^{2}$ Engenharia Ambiental e Energias Renováveis, Universidade Federal Rural da Amazônia, leticiacvaz@gmail.com;

${ }_{3}^{3}$ Agronomia, Universidade Federal Rural da Amazônia, duarte.joaocarlos17@gmail.com;

${ }^{4}$ Agronomia, Universidade Federal Rural da Amazônia, gabrmartins20@gmail.com;

${ }^{5}$ Doutorando, Universidade Federal Rural da Amazônia, ederso@uepa.br.
} 
escalas devido sua facilidade na implantação e substituição anual da cultura, onde o milho apresenta um crescimento expressivo no brasil, com o advento das tecnologias no mercado agrícola nacional.

No estudo de Veloso et al.;(2010), o estado do Pará é mencionado como sendo o maior produtor e consumidor do açaí (Euterpe oleracea Mart.), espécie frutífera e produtora de palmito na Amazônia, entretanto sua produtividade é reduzida, devido à baixa fertilidade dos solos onde são plantados.

A sistema de pastagem, usualmente, utiliza-se a queima como fonte de nutrientes para o solo, entretanto, com a repetição essa pratica de manejo diminui a qualidade da pastagem e os teores de nutrientes devido a lixiviação dos mesmo pela chuva (DICK et al.; 2008).

Para Silva et al., (2003), as análises estatísticas presentes em um estudo acarreta uma interpretação mais eficiente dos valores obtidos, entretanto, a análise dos tratamentos deve ser feita de forma rigorosa, onde as unidades experimentais sejam homogêneas e independentes entre si.

\section{Metodologia}

A área objeto deste estudo foi a fazenda Bela Vista, cuja a sede encontra-se na latitude 154'30,64" S e longitude 4853'18,54" O, na parte sul do município de Abaetetuba, estado do Pará, sendo a principal rodovia de acesso a PA-151 e está cerca 7 km da margem esquerda do Rio Moju, no sentido de sua montante à jusante, que desagua no rio Acará.

A fazenda possui cerca de 500ha de extensão, divididos em três tipos de uso e cobertura do solo, pastagem, e dois sistemas de produção milho e açaí. O estudo em questão, foi dividido em três etapas: coleta de solo, análise laboratorial e interpretação dos resultados. A amostragem seguiu os padrões estabelecidos no Manual de Amostragem de Solo, para fins de fertilidade de 2006.

A área foi dividida em módulos e cada módulo foi subdivididos 4 subáreas (piquete) para a coleta. Para cada uso e cobertura do solo foi produzida uma amostra compostas, em duas profundidades 0-20 e 20-40, sendo cada amostra composta constituída de 15 amostras simples. Todas as amostras foram alocadas em sacos plásticos de $1 \mathrm{~kg}$ para conservação e transporte. Na universidade as amostras foram secas ao ar e peneiradas em malha de $2 \mathrm{~mm}$, para dar início a segunda etapa.

A análise das amostras se deu no laboratório de química do solo da UFRA, no departamento de solos, onde foram feitas todas as análise referentes a fertilidade do solo, dentre elas os atributos químicos Alumínio Trocável $\left(\mathrm{Al}^{3+}\right)$ e Saturação por Alumínio (m\%). A metodologia se deu com base no manual de análises químicas do solo fornecido pelo laboratório, onde para determinação do alumínio 
fez-se a extração com Cloreto de Potássio a 1 molar $(\mathrm{KCl} 1 \mathrm{M})$ e titulação a com hidróxido de sódio $(\mathrm{NaOH})$, com auxílio do indicador Fenolftaleina. Os valores encontrados da variação de alumínio no solo serviram como base para o cálculo do $\mathrm{m} \%$.

Para a interpretação dos dados foi feita a tabulação dos valores obtidos para que a análise ocorresse de forma eficiente. Após isso, iniciou-se a análise estatística para validação dos resultados. Os dados foram estruturados em um Delineamento Inteiramente Casualisado (DIC) com seis tratamentos, baseado em um esquema fatorial 3x2, que refere-se ao atributo testado em três diferentes usos do solo, pastagem, milho e açaí, em duas profundidades, 0-20 e 20-40 centímetros, sendo que cada tratamento teve quatro repetições e dois atributos analisados, $\mathrm{Al}^{3+} \mathrm{e} \mathrm{m} \%$.

Para os atributos químicos do solo estudado realizou-se análise estatística de comparação de média pelo teste de Tukey ao nível de 5\% de significância, com auxílio do software Assistat versão 7.7. Utilizou-se o teste de Shapiro-Wilk (W) a 5\% de probabilidade para testar a hipótese de normalidade.

\section{Resultados e Discussões}

A análise estatística de Tukey atestou diferença a $1 \%$ de significância entre as amostras tanto para o teor de alumínio trocável $\left(\mathrm{Al}^{3+}\right)$ como para saturação por alumínio (m\%), com p-valor menor que 0,0001 e 0,0014, respectivamente. O teste de Shapiro-wilk (W) aceitou a hipótese de normalidade dos dados para ambos os atributos, sendo 24 amostras analisadas e para o teor de alumínio o Wcalculado = 0,94715 e para a saturação por alumínio o Wcalculado $=0,96107$.

Para os valores encontrados nas medias dos tratamentos (tabela 1), com relação ao alumínio trocavel observou-se uma conformidade estatística nos tratamentos referentes a pastagem e cultivo do açaí, juntamente em suas profundidades. Com relação ao teor obtido na cultura do milho, Caires et. al.;(2004), ressalta que essa cultura possui uma maior facilidade em se desenvolver em solos ácidos, entretanto com a correção do solo ocorre um aumento em sua produtividade.

Segundo Amaral e Anghinoni (2001), o acumulo de $\mathrm{Al}^{3+}$ nas camadas mais profundas ocorre devido ao fluxo de massa e/ou a complexação do alumínio por ligantes orgânicos hidrossolúveis. Contudo, independentemente da existência de materiais genéticos mais tolerantes é necessário a correção da acidez para um bom desenvolvimento das culturas (EMBRAPA, 2010).

Para analisar com maior eficiência a toxidade de um solo, deve-se calcular seu m\%. Teores de saturação por alumínio acima de 30\% causam limitações em culturas perenes, entre 30 e $50 \%$ é considerado um grau médio de toxidez, acima de 50\% o solo apresenta uma toxidade alta, sendo necessário uma correção imediata da subsuperficie do solo (EMBRAPA, 2010). Como observado 
na tabela 1, a pastagem apresenta um grau médio de toxidez, o que pode ser explicado pela baixa cobertura do solo. Já o açaí apresenta uma variação com relação a profundidade, o que caracteriza um acumulo de alumínio devido sua solubilização em função dos exsudatos radiculares. O milho, dentre os usos estudados é o que apresenta maior concentração de alumínio chegando a 61,13\%, isso ocorre devido a acidificação dos ácidos orgânicos liberados pelas plantas (SILVA et al.; 2004).

Tabela 1 - Média dos tratamentos obtidos pelo teste de Tukey ao nível de 5\% de significância e significado de cada valor (interp.), para os atributos: teor de $\mathrm{Al}^{3+}$ e saturação por alumínio (m\%).

\begin{tabular}{cllllll}
\hline Tratamento & Uso do Solo & Prof. $(\mathrm{cm})$ & $\mathrm{Al}^{3+}\left(\mathrm{cmolc} / \mathrm{dm}^{3}\right)$ & Interp. $\mathrm{Al}^{3+}$ & $\mathrm{m} \%(\%)$ & Interp. $\mathrm{m} \%$ \\
\hline 1 & \multirow{2}{*}{ Pastagem } & $0-20$ & $0,45 \mathrm{~b}$ & Baixo & $37,82 \mathrm{bc}$ & Médio \\
2 & & $20-40$ & $0,48 \mathrm{~b}$ & Baixo & $48,81 \mathrm{abc}$ & Médio \\
3 & \multirow{2}{*}{ Açaí } & $0-20$ & $0,39 \mathrm{~b}$ & Baixo & $29,59 \mathrm{c}$ & Baixo \\
4 & & $20-40$ & $0,43 \mathrm{~b}$ & Baixo & $40,60 \mathrm{bc}$ & Médio \\
5 & \multirow{2}{*}{ Milho } & $0-20$ & $0,82 \mathrm{a}$ & Médio & $49,82 \mathrm{ab}$ & Médio \\
6 & & $20-40$ & $0,98 \mathrm{a}$ & Médio & $61,13 \mathrm{a}$ & Alta \\
\hline
\end{tabular}

Fonte: autores, 2017.

Observado na figura 1 os valores com diferença significativa para $\mathrm{m} \%$, é notório que os valores para saturação por alumínio na camada mais profundas $(20-40 \mathrm{~cm})$, isso de se dá, como é relato no trabalho de Silva et al. (2004), pelo fato da acidificação promovida pela liberação de compostos orgânicos ácidos e $\mathrm{H}^{+}$pelos exsudados radiculares resultando em solubilização do alumínio presente no solo e precipitando para camada mais profunda do solo. Além disso, quando se aplica uma calagem no solo, seus resultados não são efetivos nessa profundidade, sendo uma alternativa para neutralizar o alumínio em camadas mais profundas a aplicação de gesso agrícola.

Figura 1 - Disposição gráfica dos tratamentos analisados no estudo, para os atributos: (A) teor de $\mathrm{Al}^{3+}$ e (B) saturação por alumínio $(\mathrm{m} \%)$.

A

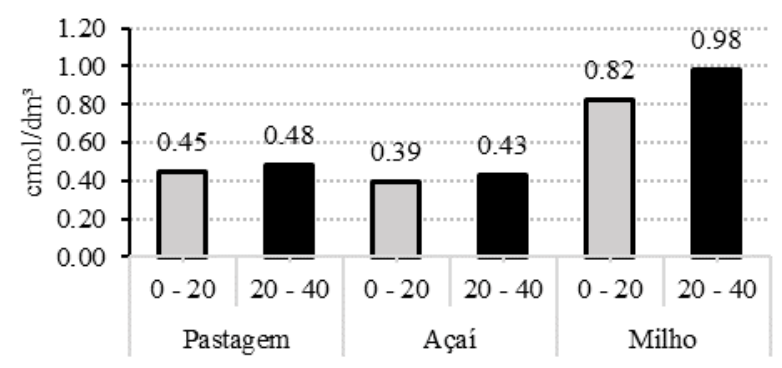

B

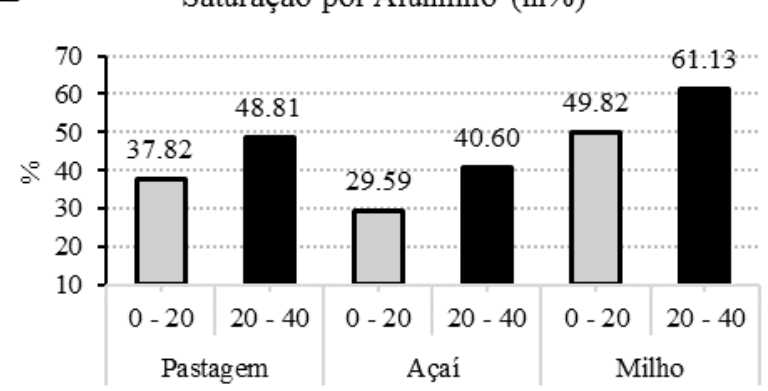

Fonte: autores, 2017.

\section{Conclusões}

Com a aplicação do estudo foi possível perceber que para o teor de alumínio trocável não 
houve diferença significativa entre as profundidades nos três usos do solo como também não houve disparidades nos resultados encontrados nos usos: pastagem e açaí. Entretanto, houve diferença entre a área plantada de milho e os outros demais usos, devido a tolerância do milho a toxidez. Já com relação a saturação por alumínio as diferenças se deram principalmente em função das profundidades, sendo que em camadas mais profundas a $\mathrm{m} \%$ é maior devido a precipitação do alumínio solubilizado pelos ácidos orgânicos em camadas mais superficiais.

\section{Referências}

AMARAL, A. S. do; ANGHINONI, I. Alteração de parâmetros químicos do solo pela reaplicação superficial de calcário no sistema plantio direto. 2001. Pesq. agropec. bras., Brasília, v. 36, n. 4, p. 695-702,. Disponível em: <http://www.scielo.br/scielo.php?pid=S0100-204X2001000400013\&script=sci_abstract\&tlng=pt>. Acesso em: 13 jan. 2017.

CAIRES, E. F. et al. Alterações químicas do solo e resposta do milho à calagem e aplicação de gesso. 2004. Revista Brasileira de Ciência do Solo, 28:125-136. Disponível em: 〈http://www.scielo.br/pdf/rbcs/v28n1/a13v28n1〉. Acesso em: 11 out. 2012.

CENTURION, J. F.; CARDOSO, J. P.; NATALE, W. Efeito de formas de manejo em algumas propriedades físicas e químicas de um Latossolo Vermelho em diferentes agroecossistemas. 2001. Revista Brasileira de Engenharia Agrícola e Ambiental, v.5, n.2, p.254-258, Campina Grande. Disponível em: <http://www.scielo.br/pdf/rbeaa/v5n2/v5n2a13>. Acesso em: 11 jan. 2017.

DICK, D. P. et al. Impacto da queima nos atributos químico e na composição química da matéria orgânica do solo e na vegetação. 2008. Pesq. agropec. bras., Brasília. v43. n5, p.633-640. Disponível em: <http://www.scielo.br/pdf/pab/v43n5/a11v43n5.pdf>. Acesso em: 11 out. 2017.

EMPRAPA, 2010. Conceitos de fertilidade do solo e manejo adequado para as regiões tropicais. ISSN 1806-3322. Disponível em: < https://www.infoteca.cnptia.embrapa.br/infoteca/handle/item/9> Acesso em: 22 jan. 2017.

MEDEIROS, A. C.; Obtenção do IQA para avaliação da qualidade da água em rios dos municípios de Abaetetuba e Barcarena (PA). 2012. 150 f. Dissertação (Mestrado) - Curso de Engenharia Civil, Pós-graduação em Engenharia Civil, Universidade Federal do Pará, Belém, 2012. Cap. 1.

NARDI, R.; CORTELLA, B. S. C. Formação de professores de Física: das intenções legais ao discurso dos formadores. In: XVI Simpósio Nacional de Ensino de Física, 2005, Rio de Janeiro. Caderno de Resumos. São Paulo - SP: Sociedade Brasileira de Física, 2005. v. 1. p. 175-175, 2005.

OLIVEIRA, M. N. de; BEZERRA, R.. Cultura do Milho. 2013. XIII Jornada de Ensino, Pesquisa e Extensão JEPEX, Recife. Disponível em: <http://www.eventosufrpe.com.br/2013/cd/resumos/R1200-1.pdf〉. Acesso em: 12 jan. 2017.

SILVA Jr. M. L.; MELO, V. S.; SILVA, G. R.; Manual de amostragem de solo para fins de fertilidade. Belém. FUNPEA, 2006. 61p.

SILVA, V. R. et al. Seção IV - Fertilidade do solo e nutrição de plantas: Variabilidade espacial das características químicas do solo e produtividade de milho em mm Argissolo Vermelho-Amarelo distrófico arênico. 2003. Revista Brasileira de Ciência do Solo, 27:1013-1020. Disponível em: 〈http://www.scielo.br/pdf/ /rbcs/v27n6/19195.pdf〉. Acesso em: 13 jan. 2017.

VELOSO, C. A. C. et al. Influência da adubação NPK na formação do açaizeiro em Latossolo Amarelo do Nordeste Paraense. 2015. Xxxv Congresso Brasileiro de Ciência do solo, Natal. Disponível em: <https://www.alice.cnptia.embrapa.br/alice/bitstream/doc/1025450/1/ResumoVeloso1.pdf>. Acesso em: 10 jan. 2017.

VELOSO, C. A. C. et al. Manejo da adubação química em açaizeiro cultivado no Nordeste Paraense. 2010. XXIX Reunião Brasileira de Fertilidade do Solo e Nutrição de Plantas, Espirito Santo. Disponível em: <https://ainfo.cnptia.embrapa.br/digital/bitstream/item/30871/1/costa-veloso-I.pdf>. Acesso em: 10 jan. 2017. 